\title{
Astragaloside attenuates the progression of prostate cancer cells through endoplasmic reticulum stress pathways
}

\author{
BO TAN ${ }^{*}$, RENFENG JIA* , GANG WANG and JINHUI YANG \\ Department of Urology, Shengli Oilfield Central Hospital, Dongying, Shandong 257034, P.R. China
}

Received August 25, 2017; Accepted February 9, 2018

DOI: $10.3892 /$ ol.2018.9071

\begin{abstract}
Astragaloside (As) has been demonstrated extensively to serve roles in a variety of tumor types, including glioma, lung cancer, colorectal cancer, breast cancer and cervical cancer, and has therefore been widely used in Traditional Chinese Medicine. To the best of our knowledge, the present study was the first to investigate the efficacy of the Traditional Chinese Medicine astragaloside on tumor growth and the apoptosis of prostate cancer cells. In addition, further investigation into the underlying molecular mechanisms via the endoplasmic reticulum(ER) stress pathway was also performed. In the present study, the human prostate cancer DU-145 cell line was employed as an experimental model in vitro and cells were divided into five treatment groups: Dimethyl sulfoxide (DMSO) group (control), low-dose astragaloside group (L-As; $20 \mathrm{nmol} / \mathrm{l}$ ), moderate-dose astragaloside group (M-As; $50 \mathrm{nmol} / \mathrm{l})$, high-dose astragaloside group (H-As, $100 \mathrm{nmol} / \mathrm{l})$ and ER stress suppressor group (tauroursodeoxycholic acid; TUDCA). The proliferative ability and apoptosis rate of the DU-145 cells were detected via Cell Counting kit- 8 methods and flow cytometry, respectively. Furthermore, the ER stress factors [binding immunoglobulin protein (BiP), C/EBP homologous protein (CHOP) and caspase-12] were assessed through reverse transcription polymerase chain reaction. Additionally, the protein expression levels of inositol-requiring enzyme 1 (IRE1), phosphorylated protein kinase R-like ER kinase (p-PERK), iron-regulated transcriptional activator Aft (AFT)4 and AFT6 were measured detected by western blot analysis. Administration of As significantly reduced the cell viability and promoted apoptosis $(\mathrm{P}<0.05)$ in a dose-dependent manner. Expression of ER-stressed genes BiP, CHOP and caspase-12 mRNA was increased by As administration, while
\end{abstract}

Correspondence to: Dr Renfeng Jia, Department of Urology, Shengli Oilfield Central Hospital, 31 Jinan Road, Dongying, Shandong 257034, P.R. China

E-mail: jiarenfengfeng@163.com

*Contributed equally

Key words: astragaloside, prostate cancer cells, endoplasmic reticulum stress pathway
TUDCA treatment led to a lower mRNA expression of these genes, compared with the control group. Results of western blot analysis indicated that the protein expression of IRE1, AFT4 and AFT6 was upregulated in the H-As group, and that the ratio of p-PERK/PERK was also higher than in the other groups. The administration of As demonstrated significant therapeutic effects on the proliferation of prostate cancer cells, as well as the expression of related proteins and genes. The results of the present study suggested future clinical potential of As for the treatment of prostate cancer.

\section{Introduction}

Prostate cancer is a type of malignant tumor developed in the prostate tissue, a gland serving pivotal roles in male reproductive system (1). The common characterization of the majority of prostate cancer cases is a slow growth without obvious symptoms $(2,3)$. However, in certain cases, prostate cancer tumor grew relatively faster and migrated to other parts of the body, including bone tissues, lymph nodes and soft tissues, if proper treatment is not applied in time $(4,5)$. With the development of cancer, clinical manifestations, including bloody urine, pelvic pain and difficulty urinating, will occur (6). In Europe, the mortality rate of the patients diagnosed with prostate cancer is the highest of the first among all types of cancer (7). In China, despite the tremendous progress of corresponding therapies to control the development of prostate cancer, the incidence rate of this disease is gradually increasing due to lifestyle changes (8). In addition, the application of traditional therapies (chemotherapy or radiation theory) is confronted with challenges, including drug tolerance and adverse side effects (9).

Astragaloside (As) is the active ingredient of the Traditional Chinese Medicine Astragalus membranaceus (10). With the proven biological activities in different physiological pathways and signaling transductions, As has been widely used in the treatment of a variety of human diseases, including breast cancer (10), glioma (11), lung cancer (12), liver fibrosis (13) and allergic inflammation (14). In addition, numerous studies have demonstrated that As may regulate ER response through multiple pathways, including the phosphorylated protein kinase R-like ER kinase (PERK)/iron-regulated transcriptional activator Aft 4 (ATF4)/C/EBP homologous protein (CHOP) pathway and thioredoxin-interacting protein/NACHT, LRR and PYD domains-containing protein 3 signaling (15-17). In view of the biological activities of as and the pathogenesis 
of prostate cancer, we hypothesized that As may also have pharmacological values in the treatment of prostate cancer.

Endoplasmic reticulum (ER) is an organelle responsible for the folding and trafficking of cellular proteins (18), which is very sensitive to intracellular chemical, physiological changes and extracellular stimuli. The aforementioned negative effects on ER may usually lead to protein misfolding, which in turn affects a variety of cellular signaling transductions in order to further induce ER stress (19). ER stress is involved in different types of cellular processes and the development of various types of human disease. Previous studies have demonstrated that the accumulation of ER mutant proteins is associated with autophagy, indicating that autophagy may be mediated by ER stress (20). Recent studies have demonstrated that ER stress may be induced by quercetin and that the induced ER stress in prostate cancer PC-3 cells contributed to the anticancer activity of quercetin (21), indicating that ER stress may potentially be a target for the treatment of prostate cancer. Wang et al (17) have reported that intravenous as attenuates proteinuria in streptozotocin-induced diabetic nephropathy via the inhibition of ER stress (17). Therefore, we hypothesized that As may protect prostate cancer DU-145 cells through the ER stress pathway. The protective effect of As on the apoptosis and proliferation of DU-145 cells was investigated. In addition, the changes in the expression of ER stress-associated factors were also detected through reverse transcription-quantitative polymerase chain reaction and western blot analysis.

\section{Materials and methods}

Cell grouping and treatments. Human prostate cancer DU-145 cells were provided by the Shanghai Institute of Cellular Biology of Chinese Academy of Sciences (Shanghai, China) and were cultured in modified Eagle's medium (Gibco; Thermo Fisher Scientific, Inc., Waltham, MA, USA), containing $10 \%$ fetal bovine serum, $2 \mathrm{mM}$ L-glutamine and $1 \%$ penicillin-streptomycin at $37^{\circ} \mathrm{C}$ in a $5 \% \mathrm{CO}_{2}$ incubator. Logarithmic-growth-phase DU-145 cells were collected to be applied in the experimental analysis. The cells were divided into 5 groups: Control group treated with $10 \mu \mathrm{l}$ dimethyl sulfoxide (DMSO) into the medium for follow-up incubation; low-dose As (L-As) group, moderate-dose As (M-As) group and high-dose As (H-As) group treated with $10 \mu \mathrm{l}$ As-DMSO solution at a concentration of 20 , 50 and $100 \mathrm{nmol} / \mathrm{l}$, respectively; and tauroursodeoxycholic acid (TUDCA) group treated with $10 \mu 1$ TUDCA-DMSO solution (EMD Millipore, Billerica, MA, USA).

Flow cytometry analysis. Flow cytometry was used to analyze the apoptotic percentage of DU-145 cells. In brief, $1 \times 10^{6}$ DU-145 cells were harvested, centrifuged at $60 \mathrm{x} \mathrm{g}$, $4^{\circ} \mathrm{C}$ for $5 \mathrm{~min}$ and resuspended in phosphate-buffered saline. Subsequently, $5 \mu \mathrm{l}$ Annexin V $(1 \mu \mathrm{g} / \mathrm{ml}$; Beckman Coulter, Inc., Brea, CA, USA) was added into cells and incubated at room temperature for $15 \mathrm{~min}$. Subsequently, propidium iodide $(1 \mu \mathrm{g} / \mathrm{ml})$ was added and incubated for $5 \mathrm{~min}$ at room temperature. All staining incubation steps were performed in the dark. Next, cell apoptosis was detected using a FC500 series flow cytometer and MXP software (version 2.2), and the data were analyzed by CXP_9.3 version software (both from Beckman Coulter, Inc. Brea, CA, USA).
Cell proliferation assay. Cells were seeded onto 96-well plates at a density of $1.0 \times 10^{4}$ cells/well. The culture medium was replaced with DMSO medium solution, H-As-DMSO medium solution (100 nmol/l) and TUDCA-DMSO medium solution for $24 \mathrm{~h}$. Subsequently, $10 \mu \mathrm{l}$ Cell Counting kit-8 solution (Dojindo Molecular Technologies, Inc., Kumamoto, Japan) was added at 12, 24, 48 and $72 \mathrm{~h}$, respectively. DU-145 cells were incubated at $37^{\circ} \mathrm{C}$ in $5 \% \mathrm{CO}_{2}$ for another $4 \mathrm{~h}$. The optical density value of each well was measured at $450 \mathrm{~nm}$ using a microplate reader (HBS-1096A; http://www.detielab.com/).

$R T$ - $q P C R$. Cells were collected from each group and the total RNA was extracted using TRIzol kit (Invitrogen; Thermo Fisher Scientific, Inc.) according to the manufacturer's protocols. The purity and integrity of total RNA were checked and reverse transcription was performed using an Easy Script First-Strand cDNA Synthesis Super Mix kit (TransGen Biotech, Co., Ltd., Beijing, China). The conditions of cDNA synthesis were as follows: $25^{\circ} \mathrm{C}, 10 \mathrm{~min}$ followed by $42^{\circ} \mathrm{C}, 30 \mathrm{~min}$ according to the manufacturer's protocol. A SYBR-Green master kit (Applied Biosystems; Thermo Fisher Scientific, Inc.) and $1 \mu \mathrm{l}$ cDNA were used to prepare the PCR reaction system. All mRNA quantification data were normalized to $\beta$-actin using the $2^{-\Delta \Delta \mathrm{Cq}}$ method (22).

The sequences of the primers used were as follows: BiP forward, 5'-GGTATTGAAACTGTGGGAGGT G-3' and reverse, 5'-GATTGTCTTTTGTCAGGGGTC T-3'; CHOP forward, 5'-CTGAGTCATTGCCTTTCTCCT T-3' and reverse, 5'-CCACTTTCCTTTCATTCTCCTG-3'; caspase-12 forward, 5'-GAAGGAATCTGTGGGGTGAA-3' and reverse, 5'-TCCCTTTGCTTGTGGGATACC-3'; and $\beta$-actin forward, 5'-TGGCACCCAGCACAATGAA-3' and reverse, 5'-CTAAGTCATAGTCCGCCTAGAAGCA-3'. The reaction conditions were as follows: $94^{\circ} \mathrm{C}$ for $5 \mathrm{~min}$, followed by 35,37 or 40 cycles of $94^{\circ} \mathrm{C}$ for $30 \mathrm{sec}, 53^{\circ} \mathrm{C}$ for $30 \mathrm{sec}$ and $72^{\circ} \mathrm{C}$ for $30 \mathrm{sec}$. The reaction was performed using a RT-qPCR instrument (Biometra GmbH, Göttingen, Germany).

Western blot analysis. The total protein was extracted using Protein Extraction Buffer (Bioo Scientific Corporation, Austin, TX, USA) and the concentration was measured using bicinchoninic acid protein quantification kit (Pierce; Thermo Fisher Scientific, Inc.). The protein $(40 \mu \mathrm{g})$ from the samples of each group was subjected to $10 \%$ SDS-PAGE, prior to being transferred onto polyvinylidene difluoride membranes. Next, the membranes were blocked with $5 \%$ skimmed milk for $1 \mathrm{~h}$ and incubated overnight at $4^{\circ} \mathrm{C}$ with the following primary antibodies diluted in bovine serum albumin solution $(50 \mathrm{~g} / \mathrm{l})$ : Rabbit anti-human IRE1 polyclonal antibody (dilution, 1:1,000; no. ab37073, Abcam, Cambridge, UK), rabbit anti-human p-PERK and PERK polyclonal antibodies (dilution, 1:500; no. sc-32577 and sc-13073, Santa Cruz Biotechnology, Inc., Dallas, TX, USA), and rabbit anti-human AFT4 and AFT6 antibodies (dilution, 1:200; no. 11815 and 65880, Cell Signaling Technology, Inc., Danvers, MA, USA) at $4^{\circ} \mathrm{C}$ overnight. Following washing with TBST (TBS, with $1 \mathrm{ml} / 1$ Tween-20) 3 times (for 5 min each time), membranes were incubated with horseradish peroxidase-conjugated goat anti-rabbit secondary antibody (dilution, 1:10,000; ab6721; Abcam) for $1 \mathrm{~h}$ at room temperature. Protein expression was detected using an enhanced 
A

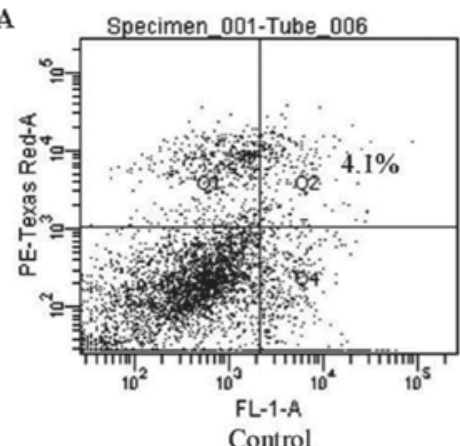

C

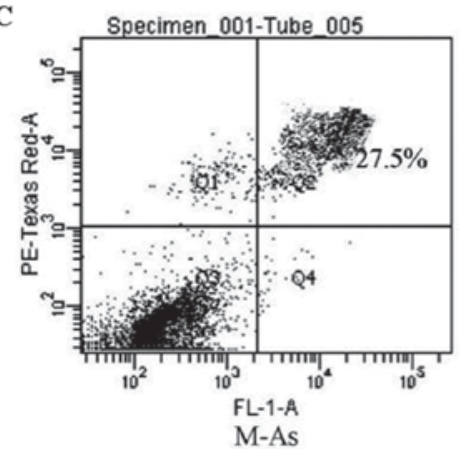

E

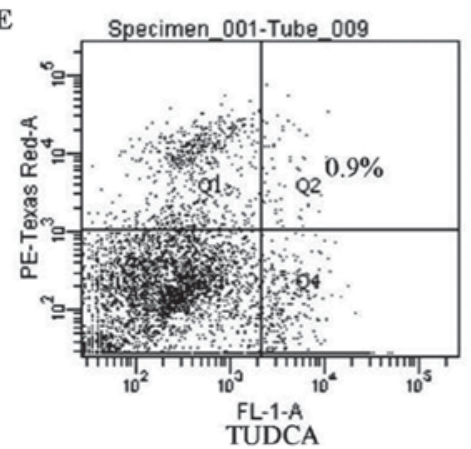

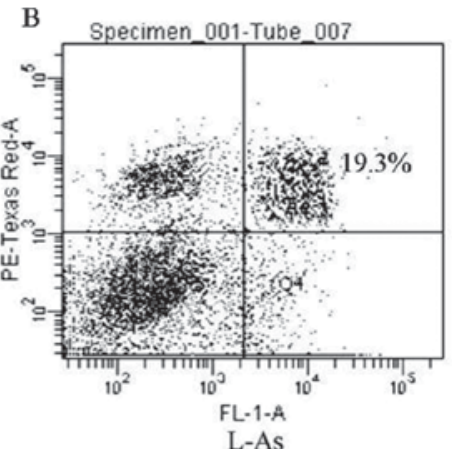

D Specimen_001-Tube_008

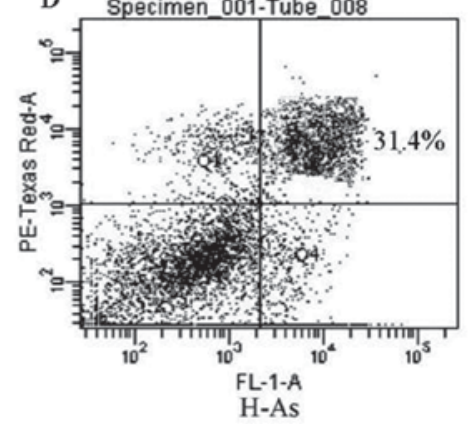

F

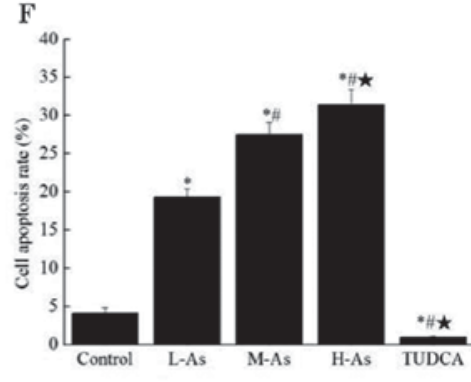

Figure 1. The cell apoptosis rate analyzed by flow cytometry. (A) Control group, (B) L-As group, (C) M-As group, (D) H-As group and (E) TUDCA group, (F) quantitative bar graph illustrating the cell apoptosis rate. DU-145 cells were treated with $10 \mu 1$ DMSO, As-DMSO solution with a concentration of 20,50 and $100 \mathrm{nmol} / 1$, respectively, and TUDCA-DMSO solution. Data are presented as the mean \pm standard deviation $(\mathrm{n}=5)$. ${ }^{*} \mathrm{P}<0.05$, compared with the control group; ${ }^{\#} \mathrm{P}<0.05$, compared with the L-As group; ${ }^{\star} \mathrm{P}<0.05$, compared with the M-As group. L-As, low-dose astragaloside; M-As, moderate-dose astragaloside; $\mathrm{H}-\mathrm{As}$, high-dose astragaloside; TUDCA, tauroursodeoxycholic acid; DMSO, dimethyl sulfoxide.

chemiluminescent agent (Boster Biological Technology, Pleasanton,CA,USA).Protein expression levels were normalized to GAPDH and ImageJ 2.1 software (National Institutes of Health, Bethesda, MD, USA) was used to scan and quantify the gray values.

Statistical analyses. Data are presented as the mean \pm standard deviation and were analyzed using SPSS 19.0 statistical software (IBM Corp., Armonk, NY, USA). Differences among multiple groups were assessed using one-way analysis of variance, followed by Dunnett's method. $\mathrm{P}<0.05$ was considered to indicate a statistically significant difference.

\section{Results}

Application of as promotes the apoptosis of prostate cancer cells in a dose-dependent manner. Analysis of cell apoptosis using a flow cytometry assay demonstrated that As accelerated the apoptosis of DU-145 cells in a dose-dependent manner, with a significant increase in the rate of apoptosis at concentrations of 20, 50 and $100 \mathrm{nmol} / \mathrm{l}$ (Fig. $1 ; \mathrm{P}<0.05$ ). This result indicated that As administration significantly increased the percentage of apoptosis $(\mathrm{P}<0.05)$ in As-treated groups, particularly in the H-As group, compared with that in the control group. However, treatment with TUDCA exhibited a weaker effect on the promotion of apoptosis. The results of the present study suggested that as was able to promote the apoptosis of prostate cancer cells in a dose-dependent manner.

Application of as inhibits the proliferation of prostate cancer cells. Next, the cell proliferation of DU-145 cells in the control group, H-As group and TUDCA group was measured at different time point. As demonstrated in Fig. 2, TUDCA induced a slight inhibitory effect on the viability of DU-145 cells $(0.874 \%)$, consistent with the result of the flow cytometric analysis. However, compared with the control group, as treatment significantly inhibited cell proliferation $(0.368 \%$ at $72 \mathrm{~h} ; \mathrm{P}<0.05)$ in a time-dependent manner. These results suggested that as may inhibit the proliferation of prostate cancer cells, there by inhibiting tumor development. 
Application of as increases the expression of BiP, CHOP and caspase-12 mRNA in prostate cancer cells. In order to elucidate the underlying mechanism of As activity through ER stress pathway in prostate cancer cells, the mRNA levels of BiP, CHOP and caspase-12 following treatment with $100 \mathrm{nmol} / \mathrm{l}$ As were assessed (Fig. 3). Compared with the control group, the mRNA levels of BiP, CHOP and caspase-12 were significantly increased $(\mathrm{P}<0.05)$ in $\mathrm{H}$-As group by 1.63 -fold, 2.04 -fold and 1.90 -fold, respectively. Furthermore, the expression of these mRNA in the TUDCA group was significantly decreased. Taken together, these results suggested that as increased the expression of $\mathrm{BiP}$, CHOP and caspase-12 mRNA through the ER stress pathway.

Application of as increased the levels of IRE1, p-PERK, AFT4 and AFT6 protein in prostate cancer cells. The expression levels of IRE1, p-PERK, AFT4 and AFT6, were detected in DU-145 cells through western blot analysis (Fig. 4). As demonstrated in Fig. 4A, the protein bands indicated expression of IRE1, p-PERK, AFT4 and AFT6 in the three groups. Additionally, the quantified results are displayed in Fig. 4B. The results indicated that the expression of IRE1, AFT4 and AFT6 protein were significantly increased following treatment with As (Fig. 4A and B; P<0.05). However, the level of these proteins in the TUDCA group was extremely lower than that in the control group and the TUDCA group. Additionally, the ratio of p-PERK/PERK (Fig. 4C) was also calculated, indicating that the ratio of $\mathrm{p}-\mathrm{PERK} / \mathrm{PERK}$ in the H-As group was significantly $(\mathrm{P}<0.05)$ higher than that in control group. These results indicated that as application may increase the expression of IRE1, AFT4 and AFT6, which are important proteins in the ER stress pathway, and that As is also able to increase the phosphorylation of PERK without affecting the level of PERK, which in turn increases the p-PERK/PERK ratio.

\section{Discussion}

Appropriate responses to ER stress are fundamentally important in order for cells to maintain normal physiological and biochemical functions (23). However, abnormal ER stress may also cause cell apoptosis, thereby reducing bodily functions and inducing the development of various diseases, including diabetes, neurodegenerative diseases, renal disease and atherosclerosis (24). Despite the adverse effects of ER stress on the health of the body, ER stress-based therapies are widely used in the treatment of cancer due to their ability to induce cancer cell apoptosis. Nawrocki et al (25) reported that Bortezomib was able to inhibit the function of protein kinase R-like ER kinase and to promote cell apoptosis in human pancreatic cancer cells by increasing ER stress. In addition, in the treatment of gastric cancer, the anticancer effects of WZ35 was also revealed to be correlated with its ability to induce Jun N-terminal kinase signaling transduction and ER stress-related apoptotic pathways (26). Recently, Liu et al (21) revealed that the anticancer activity of quercetin was also positively associated with the enhanced ER stress in prostate cancer PC-3 cells (21). From the aforementioned studies, we hypothesized that induction of ER stress in prostate cancer cells may potentially be used in the treatment of prostate cancer.

As has been widely used in the treatment of different types of cancer. In the treatment of breast cancer, As III was revealed

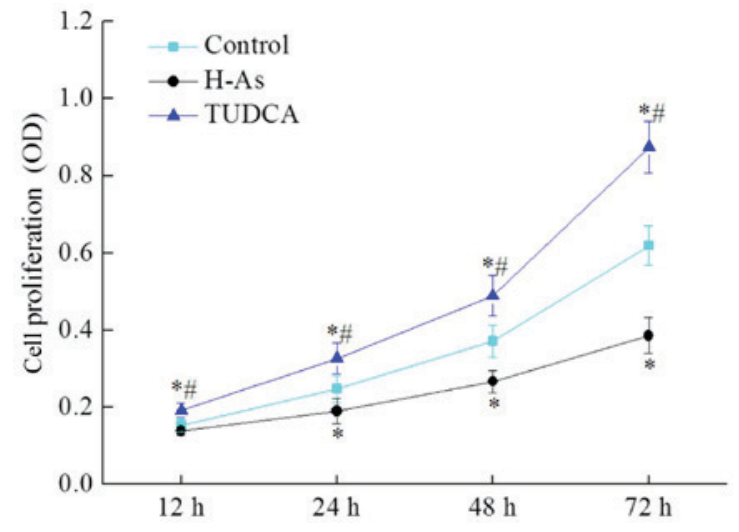

Figure 2. Astragaloside inhibited the proliferation of prostate cancer cells. The proliferation of DU-145 cells was measured using a Cell Counting kit- 8 assay at different time points $(12,24,48$ or $72 \mathrm{~h})$. Data are presented as the mean \pm standard deviation $(n=5) .{ }^{*} \mathrm{P}<0.05$, compared with the control group; ${ }^{\#} \mathrm{P}<0.05$, compared with the $\mathrm{H}$-As group. H-As, high-dose astragaloside; TUDCA, tauroursodeoxycholic acid; OD, optical density.

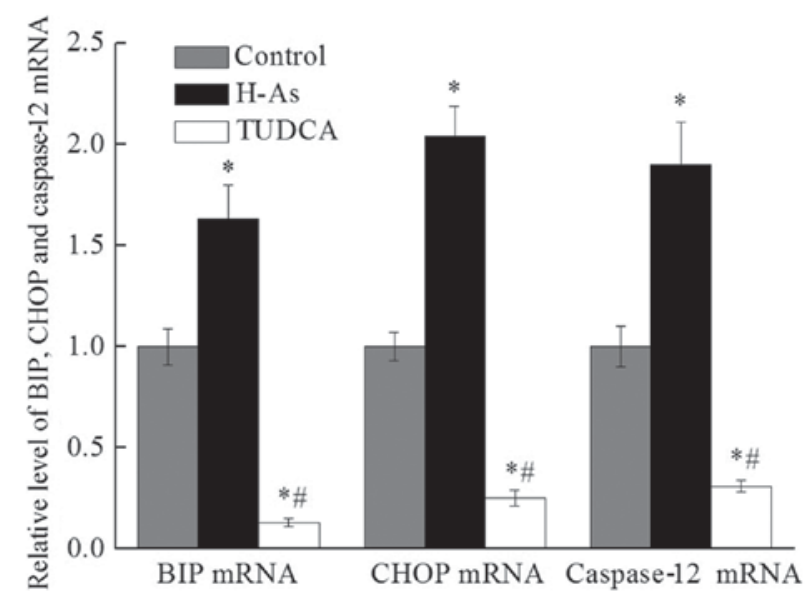

Figure 3. The relative expression of BiP, CHOP and caspase-12 mRNA in the control, H-As and TUDCA groups, as determined using reverse transcription-quantitative polymerase chain reaction. $\beta$-actin mRNA was used as endogenous control. Data are presented as the mean \pm standard deviation. ${ }^{*} \mathrm{P}<0.05$, compared with the control group; ${ }^{\#} \mathrm{P}<0.05$, compared with the $\mathrm{H}-\mathrm{As}$ group. BiP, binding immunoglobulin protein; $\mathrm{CHOP}, \mathrm{C} / \mathrm{EBP}$ homologous protein; H-As, high-dose astragaloside; TUDCA, tauroursodeoxycholic acid.

to be able to effectively decrease the survival rate of cancer cells in vitro and to reduce the growth rate of tumors in vivo by inducing cell apoptosis-related signaling pathways (10). A previous study also revealed that As IV may inhibit the invasion and migration of the human lung cancer A549 cell line by regulating the protein kinase C- $\alpha /$ ERK1/2/nuclear factor- $\mathrm{\kappa B}$ pathway (27). However, to the best of our knowledge, the application of As in the treatment of prostate cancer has yet to be reported. Therefore, the present study primarily investigated the roles of the ER stress signaling pathway in the As-mediated cell death of human prostate cancer DU-145 cells. It was revealed that as $(20-100 \mathrm{nmol} / \mathrm{l})$ promoted the apoptosis of prostate cancer cells in a dose-dependent manner. In the present study, a concentration of $100 \mathrm{nmol} / \mathrm{l}$ was selected for further study. In addition to the activity of As in inducing cell death, As may also inhibit cell proliferation. The results of the present study suggested that As may be used to treat prostate 
A
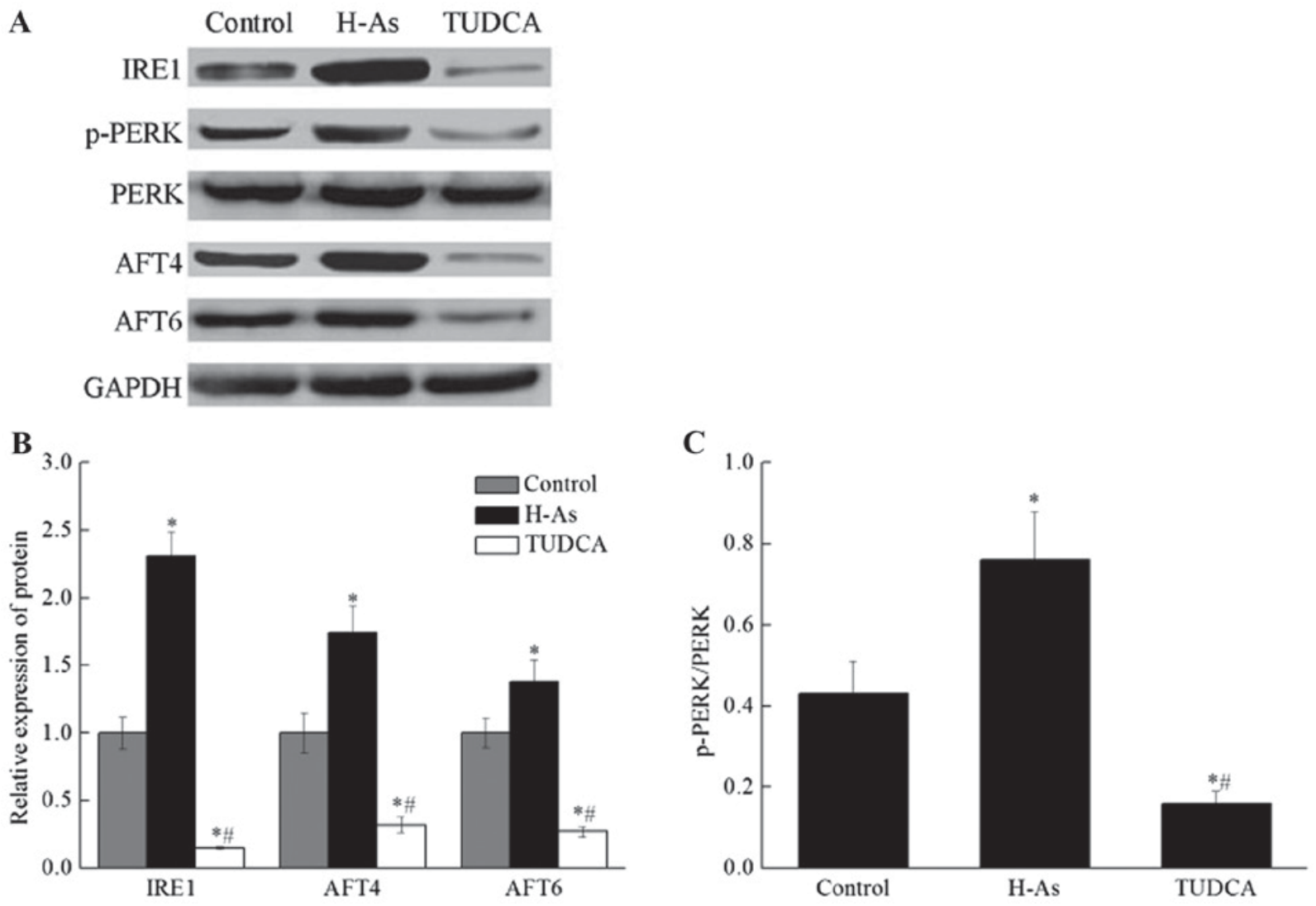

Figure 4. The levels of IRE1, PERK, p-PERK, AFT4 and AFT6 protein in the control, H-As and TUDCA groups. (A) Western blot and (B) densitometric analyses were performed to detect the protein expression of IRE1, p-PERK, PERK, AFT4 and AFT6. (C) The ratio of p-PERK/PERK in the control, H-As and TUDCA groups. All protein quantification data were normalized to GAPDH. Data are presented as the mean \pm standard deviation. "P $<0.05$, compared with the control group; ${ }^{~} \mathrm{P}<0.05$, compared with the H-As group. IRE1, inositol-requiring enzyme 1; PERK, protein kinase R-like endoplasmic reticulum kinase; p-PERK, phosphorylated PERK; AFT, iron-regulated transcriptional activator Aft; H-As, high-dose astragaloside; TUDCA, tauroursodeoxycholic acid.

cancer due to its effects in the apoptosis and proliferation of cancer cells.

Furthermore, there were a number of studies reporting the association between as and ER stress-induced cell apoptosis in various models and physiological pathways, for example Chen et al (15) and Bouman et al (28) reported the downregulation of PERK/ATF4/CHOP pathway by As IV treatment, further inhibiting the ER stress-induced podocyte apoptosis in diabetic rats. Cycloastragenol and As IV, which are active ingredients of Astragalus membranaceus, were revealed to have almost equal efficiency in inhibiting ROS-associated ER stress, which in turn regulates the activity of AMPK and inhibits the TXNIP/NLRP3 inflammasome (receptors and sensors of the innate immune system that may induce inflammation molecules derived from host proteins and infectious microbes, and may regulate caspase-1 activation) activation (29). Despite the wide application of As in the treatment of various types of cancer, the association between the anticancer activity of As and ER stress has not been reported in prostate cancer. Certain studies have demonstrated that IRE1, PERK and ATF4 are the key players in ER stress (30). Under normal conditions, ER stress factor $\mathrm{BiP}$ is able to bind to IRE1, PERK and ATF6 in order to stay in an inactive state, while the external stimuli lead to overexpression of BiP, which in turn affects the ER stress-related apoptotic pathways, including ATF4/CHOP, caspase-12, autophagy and RIDD (31). In the present study, as was revealed to be able to increase the protein expression of IRE1, p-PERK (the active form of PERK), AFT4 and AFT6 in prostate cancer cells without affecting the total level of PERK. In addition, as also increased the expression levels of BiP, CHOP and caspase-12 mRNA in prostate cancer cells. These results indicated that as may serve a role through the ER stress pathway in prostate cancer cells and may activate the ER stress-related apoptotic pathways.

In conclusion, the results of the present study demonstrated that prostate cancer was sensitive to As through activation of the ER stress pathway. These observations indicated that As upregulated the expression levels of related proteins and genes, providing a novel therapeutic approach for the treatment of prostate cancer.

\section{Acknowledgements}

Not applicable.

\section{Funding}

No funding received.

\section{Availability of data and materials}

The datasets used and/or analyzed during the current study are available from the corresponding author on reasonable request. 


\section{Authors' contributions}

BT and RJ conceived and designed the experiments; BT, RJ and GW performed the experiments; JY analyzed the data; GW and JY wrote the paper and substantively revised it. All authors read and approved the final manuscript.

\section{Ethics statement and consent to participate}

Not applicable.

\section{Patient consent for publication}

Not applicable.

\section{Competing interests}

The authors declare that they have no competing interest to declare.

\section{References}

1. DeSantis CE, Lin CC, Mariotto AB, Siegel RL, Stein KD, Kramer JL, Alteri R, Robbins AS and Jemal A: Cancer treatment and survivorship statistics, 2014. CA Cancer J Clin 64: 252-271, 2014.

2. Nyquist MD and Dehm SM: Interplay between genomic alterations and androgen receptor signaling during prostate cancer development and progression. Horm Cancer 4: 61-69, 2013.

3. Hamid AR, Hoogland AM, Smit F, Jannink S, van Rijt-van de Westerlo C, Jansen CF, van Leenders GJ and Verhaegh GW: The role of HOXC6 in prostate cancer development. Prostate 75: 1868-1876, 2015.

4. Crawford ED, Stone NN, Evan YY, Koo PJ, Freedland SJ, Slovin SF, Gomella LG, Berger ER and Keane TE: Challenges and recommendations for early identification of metastatic disease in prostate cancer. Urology 83: 664-669, 2014.

5. Rustin GJ, Bast RC Jr, Kelloff GJ, Barrett JC, Carter SK, Nisen PD, Sigman CC, Parkinson DR and Ruddon RW: Use of CA-125 in clinical trial evaluation of new therapeutic drugs for ovarian cancer. Clin Cancer Res 10: 3919-3926, 2004.

6. Victorson DE, Brucker PS, Bode RK, Eton DT, Talcott JA, Clark JA, Knight SJ, Litwin MS, Moinpour CM, Reeve BB, et al Ensuring comprehensive assessment of urinary problems in prostate cancer through patient-physician concordance. Urol Oncol 32: 26.e25-e31, 2014.

7. Schröder FH, Hugosson J, Roobol MJ, Tammela TL, Zappa M, Nelen V, Kwiatkowski M, Lujan M, Määttänen L, Lilja H, et al: Screening and prostate cancer mortality: results of the European Randomised Study of Screening for Prostate Cancer (ERSPC) at 13 years of follow-up. Lancet 384: 2027-2035, 2014.

8. Chen W, Zheng R, Baade PD, Zhang S, Zeng H, Bray F, Jemal A, $\mathrm{Yu}$ XQ and He J: Cancer statistics in China, 2015. CA Cancer J Clin 66: 115-132, 2016

9. Freytag SO, Stricker H, Lu M, Elshaikh M, Aref I, Pradhan D, Levin K, Kim JH, Peabody J, Siddiqui F, et al: Prospective randomized phase 2 trial of intensity modulated radiation therapy with or without oncolytic adenovirus-mediated cytotoxic gene therapy in intermediate-risk prostate cancer. Int J Radiat Oncol Biol Phys 89: 268-276, 2014.

10. Wang S, Tang L and Chen F: Astragaloside III from Astragalus membranaceus antagonizes breast cancer growth. AJTCAM 12: 183-186, 2015.

11. Li B, Wang F, Liu N, Shen W and Huang T: Astragaloside IV inhibits progression of glioma via blocking MAPK/ERK signaling pathway. Biochem Biophys Res Commun 491: 98-103, 2017.

12. Dai PC, Liu DL, Zhang L, Ye J, Wang Q, Zhang HW, Lin XH and Lai GX: Astragaloside IV sensitizes non-small cell lung cancer cells to gefitinib potentially via regulation of SIRT6. Tumour Biol 39: 1010428317697555, 2017.
13. Yongping M, Zhang X, Xuewei L, Fan W, Chen J, Zhang H, Chen G, Liu C and Liu P: Astragaloside prevents BDL-induced liver fibrosis through inhibition of notch signaling activation. J Ethnopharmacol 169: 200-209, 2015.

14. Huang X, Tang L, Wang F and Song G: Astragaloside IV attenuates allergic inflammation by regulation Th1/Th2 cytokine and enhancement CD4+ CD25+ Foxp3 T cells in ovalbumin-induced asthma. Immunobiology 219: 565-571, 2014.

15. Chen Y, Gui D, Chen J,He D, Luo Y and Wang N: Down-regulation of PERK-ATF4-CHOP pathway by Astragaloside IV is associated with the inhibition of endoplasmic reticulum stress-induced podocyte apoptosis in diabetic rats. Cell Physiol Biochem 33: 1975-1987, 2014

16. Zhao Y, Li Q, Zhao W, Li J, Sun Y, Liu K, Liu B and Zhang N: Astragaloside IV and cycloastragenol are equally effective in inhibition of endoplasmic reticulum stress-associated TXNIP/NLRP3 inflammasome activation in the endothelium. J Ethnopharmacology 169: 210-218, 2015

17. Wang ZS, Xiong F, Xie XH, Chen D, Pan JH and Cheng L: Astragaloside IV attenuates proteinuria in streptozotocin-induced diabetic nephropathy via the inhibition of endoplasmic reticulum stress. BMC Nephrol 16: 44, 2015.

18. Cao SS and Kaufman RJ: Endoplasmic reticulum stress and oxidative stress in cell fate decision and human disease. Antioxid Redox Sign 21: 396-413, 2014.

19. Gardner BM, Pincus D, Gotthardt K, Gallagher CM and Walter P: Endoplasmic reticulum stress sensing in the unfolded protein response. Cold Spring Harb Perspect Biol 5: a013169, 2013.

20. Deegan S, Saveljeva S, Gorman AM and Samali A: Stress-induced self-cannibalism: On the regulation of autophagy by endoplasmic reticulum stress. Cell Mol Life Sci 70: 2425-2441, 2013

21. Liu KC, Yen CY, Wu RS, Yang JS, Lu HF, Lu KW, Lo C, Chen HY, Tang NY, Wu CC and Chung JG: The roles of endoplasmic reticulum stress and mitochondrial apoptotic signaling pathway in quercetin-mediated cell death of human prostate cancer PC-3 cell. Environ Toxicol 29: 428-439, 2014.

22. Livak KJ and Schmittgen TD: Analysis of relative gene expression data using real-time quantitative PCR and the 2(-Delta Delta C(T)) method. Methods 25: 402-408, 2001

23. Hetz C: The unfolded protein response: Controlling cell fate decisions under ER stress and beyond. Nat Rev Mol Cell Biol 13: 89-102, 2012.

24. Tabas I and Ron D: Integrating the mechanisms of apoptosis induced by endoplasmic reticulum stress. Nat Cell Biol 13: 184-190, 2011.

25. Nawrocki ST, Carew JS, Dunner K Jr, Boise LH, Chiao PJ, Huang P, Abbruzzese JL and McConkey DJ: Bortezomib inhibits PKR-like endoplasmic reticulum (ER) kinase and induces apoptosis via ER stress in human pancreatic cancer cells. Cancer Res 65: 11510-11519, 2005.

26. Zou P, Zhang J, Xia Y, Kanchana K, Guo G, Chen W, Huang Y, Wang Z, Yang S and Liang G: ROS generation mediates the anti-cancer effects of WZ35 via activating JNK and ER stress apoptotic pathways in gastric cancer. Oncotarget 6: 5860-5876, 2015.

27. Cheng $\mathrm{X}$, Gu J, Zhang M, Yuan J, Zhao B, Jiang J and Jia X: Astragaloside IV inhibits migration and invasion in human lung cancer A549 cells via regulating PKC- $\alpha$-ERK1/2-NF- $\kappa \mathrm{B}$ pathway. Int Immunopharmacol 23: 304-313, 2014.

28. Bouman L, Schlierf A, Lutz AK, Shan J, Deinlein A, Kast J, Galehdar Z, Palmisano V, Patenge N, Berg D, et al: Parkin is transcriptionally regulated by ATF4: Evidence for an interconnection between mitochondrial stress and ER stress. Cell Death Differ 18: 769-782, 2011.

29. Zhao Y, Li Q, Zhao W, Li J, Sun Y, Liu K, Liu B and Zhang N: Astragaloside IV and cycloastragenol are equally effective in inhibition of endoplasmic reticulum stress-associated TXNIP/NLRP3 inflammasome activation in the endothelium. J Ethnopharmacol 169: 210-218, 2015.

30. Liu ZW, Zhu HT, Chen KL, Dong X, Wei J, Qiu C and Xue JH: Protein kinase RNA-like endoplasmic reticulum kinase (PERK) signaling pathway plays a major role in reactive oxygen species (ROS)-mediated endoplasmic reticulum stress-induced apoptosis in diabetic cardiomyopathy. Cardiovasc Diabetol 12: 158, 2013.

31. Jheng JR, Ho JY and Horng JT: ER stress, autophagy and RNA viruses. Front Microbiol 5: 388, 2014. 